\title{
Interaction Between Two Exotic Invading Species: Endozoochory of Acacia farnesiana Seeds by the European Rabbit (Oryctolagus cuniculus)
}

\author{
Marcos Salas ${ }^{*}, 1$, Silvia Fernández-Lugo ${ }^{2}$ and Agustín Naranjo ${ }^{3}$ \\ ${ }^{I}$ Especies Invasoras: Grupo de Investigación Interinsular, Spain \\ ${ }^{2}$ Departamento de Ecología, Facultad de Biología, Universidad de La Laguna, La Laguna, 38206, Spain \\ ${ }^{3}$ Departamento de Geografia, Facultad de Geografia e Historia, Universidad de Las Palmas de Gran Canaria, Las \\ Palmas de Gran Canaria 35003, Spain
}

\begin{abstract}
The question of how plant species foreign to a biological system can disperse and turn into an environmental problem is very important for the control of the invasive plant species, especially for insular ecosystems, which are more susceptible to biological invasions. We analyzed the role played by the European rabbit (Oryctolagus cuniculus) in the seed dispersal of the invasive scrub Acacia farnesiana in Gran Canaria (Canary Islands). The results indicated that $A$. farnesiana is a food resource that rabbits use all year long. We found a high percentage of undamaged seeds $(9.77 \%)$ in rabbit's pellets. Although the passage through the rabbit gut did not increase the germination rate of the seeds, it seems to increase their germination speed. We concluded that rabbits are able to disperse A. farnesiana seeds by endozoochory, making the invasion process faster and successful.
\end{abstract}

Keywords: Acacia farnesiana, Oryctolagus cuniculus, invasive species, endozoochory.

\section{INTRODUCTION}

Mutual interaction between invasive species is relatively frequent and is called the invasion complex [1]. The formation of these complexes can facilitate the survival and the ecological impact of the interacting species; this process is known as "invasional meltdown" [2]. The study of these complexes and their impact on the dispersion of species are considered of prime importance in invasive species research [3].

The scrub species Acacia farnesiana and the European rabbit (Oryctolagus cuniculus) are considered invasive in several regions around the world. The European rabbit acts as an endozoochorous seed disperser of different species of plants in its area of origin [4-12], such as the leguminous shrubs Retama sphaerocarpa and $R$. monosperma [13], as well as in areas where it is has been introduced [14, 15]. Some of the species of the Acacia genus, characterised by indehiscent fruits, long thorns and foliage leaves [16] have in the herbivorous mammals their principal agents of dispersion [17-19], however the benefits of the endozoochory for these plants has occasionally been questioned [20].

A. farnesiana appears several times in previous works about the invasive exotic species of the Canary Islands [21, 22], although these works considered other species of the genus like A. cyclops or A. saligna, more commonly called "acacias majoreras", much more dangerous than $A$. farnesiana. However, in spite of the shortage of data in the published bibliography about $A$. farnesiana in the Canary Islands, this species occupies considerable gardens. It is even

*Address correspondence to this author at the Especies Invasoras: Grupo de Investigación Interinsular, Spain; Tel: +34928451728; Fax: +34928451308; E-mail:yamilee@teleline.es established in natural territories away from human disturbances, where it is competing with the native species for the space and resources. Currently A. farnesiana is most commonly found in mountainsides and ravines, although in many areas they are starting to invade the riverbeds. The increasing distribution of this species leads us to think that it has a large invasion capacity, and that it is urgent to study the mechanism by which it is dispersing.

The main hypotheses of this study are that the European rabbit is acting as a dispersal agent of the A. farnesiana seeds in the studied zone and that the endozoochory by rabbits increases the germination rate of these seeds.

\section{MATERIALS AND METHODOLOGY}

\section{The Study}

The study was carried out in the Arguineguín ravine (Fig. 1a, b). It is the largest ravine in the south of Gran Canaria ( $28 \mathrm{R}$ 434435,3073170 ) and it is located in the middle of the island with a North-South orientation, $25 \mathrm{~km}$ long and about $1.500 \mathrm{~m}$ from top to sea level, which is a strong average inclination. The annual precipitation of the area is lower than $1501 / \mathrm{m}^{2}$, concentrated in just a few days. In the middle of the ravines there are several small dams that can modify the water flow. The potential vegetation is a xerophyllic shrubland dominated by Euphorbia canariensis, E. basamifera and E. regis-jubae in the plateau and at the bottom of the ravine is common to find Tamarix canariensis stands, and in the flooding areas Juncus acutus and Typha domingensis. Although the plant community in the area is under water stress, it is fairly well conserved and extensive; invasive species and some human disturbance are the main threats. 
(a)

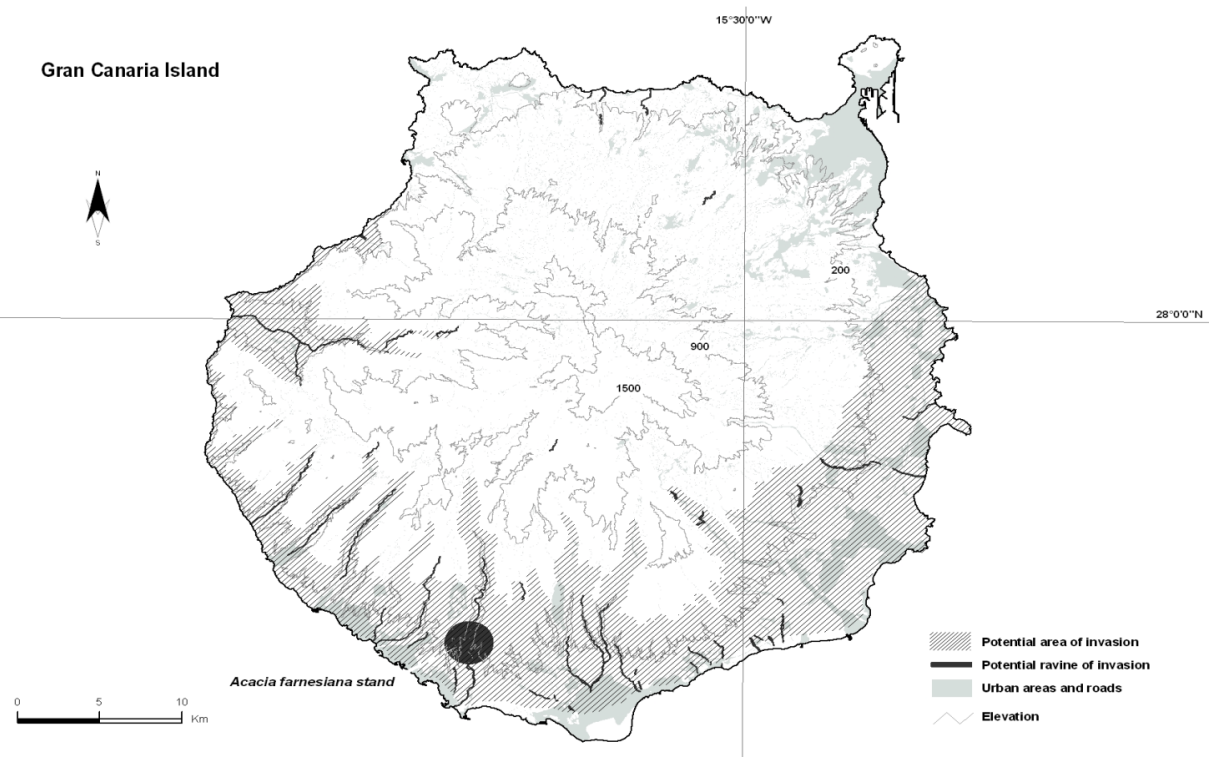

(b)

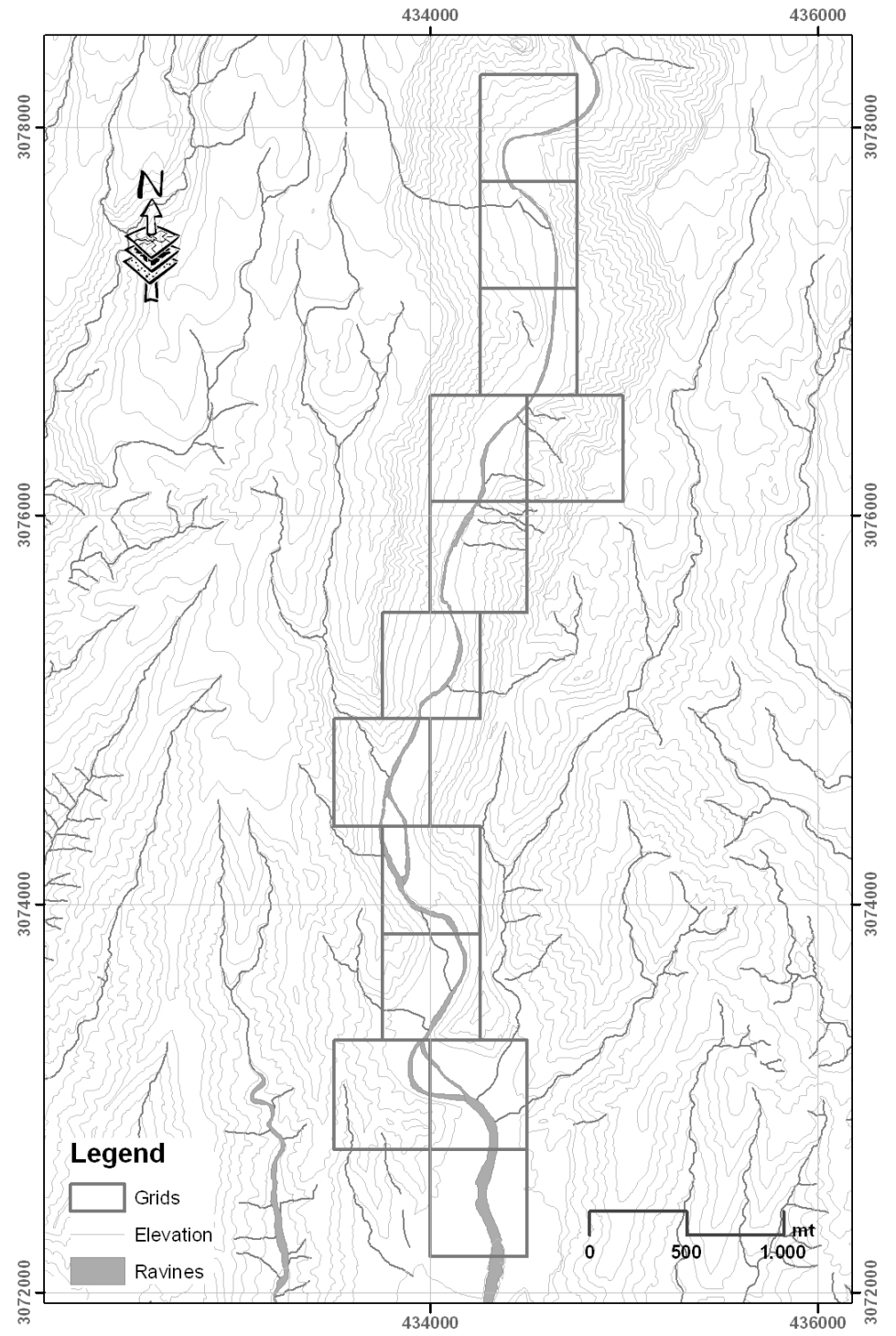

Fig. (1). Location of the study site in Gran Canaria island (a) and a detailed map of the studied ravine (b). 
The study site was placed in the lower section of the ravine from $120 \mathrm{~m}$ a.s.l. to $25 \mathrm{~m}$ a.s.l., having a total length of $5.5 \mathrm{~km}$. In this area the ravine bed has a width between $100 \mathrm{~m}$ and $200 \mathrm{~m}$, with boulders that the water flows seasonally and terraces.

\section{Experiment Design}

The study site was divided into 13 plots of $500 \mathrm{~m} \times 500$ $\mathrm{m}$ in size. In each plot a minimum of 100 fresh and intact adult rabbit faeces were collected from a minimum of 4 different latrines. The sampling was carried out in the four different seasons from autumn 2007 to summer 2008 in order to determine if there are seasonal variations in the use of A. farnesiana as a food resource by the rabbits. Simultaneously with the excrement collections, mature fruits of $A$. farnesiana, from at least 30 different plants, were collected in the same area to be used as control in the germination tests. The A. farnesiana seeds were obtained from the pellets by manual extraction and separated between intact and damaged or partially digested seeds. The apparently viable seeds and their respective controls were placed in petri dishes with blotting paper. Petri dishes were periodically moistened and maintained in a germination chamber under controlled light and temperate conditions (14 hours light with a level of $14000 \mathrm{~lx}$ and a constant temperature of $21^{\circ} \mathrm{C}$ ) for 85 days. We recorded the germinated seeds daily, using radicle emergence as the germination criterion.

\section{Statistical Analysis}

We applied the non parametric U-Mann-Whitney test (for a $\mathrm{p}<0.05$ ) to look for significant differences in the germination rate between the ingested and control seeds in the different seasons. The Kruskal-Wallis test (for a $\mathrm{p}<0.05$ ) was used to detect differences in the percentage of seeds found in the rabbit faeces between seasons, as well as to find out if there were differences in the germination rates of the ingested and control seeds between seasons. Statistical methods followed Zar [23] and were implemented by mean of the statistical package SPSS [24].

\section{RESULTS}

A total of 7,080 pellets were collected during the study period, from which $792(11.19 \%)$ contained A. farnesiana seeds. The highest number of rabbit faeces $(2,004)$ was collected in autumn while the smallest amount $(1,577)$ was collected in spring (Table 1). This difference could be due to the fluctuation of the rabbit populations during the hunting season and to the migratory movements within the studied territory. We did not find differences $\left(\mathrm{N}=13 ; \mathrm{X}^{2}=2.42 ; \mathrm{p}>\right.$ 0.05 ) in the percentage of pellets containing seeds between the different seasons, which indicates that A. farnesiana is a food resource that the rabbits use all year long.

Of the 792 seeds found, $12.62 \%$ were damaged or partially digested. Most of the unviable seeds had parasitism signs; probably due to attack by coleopterans, as it happened in other cases of interactions between acacias and herbivores [25]. The action of the parasitic beetle can favour the digestion of the seeds, diminishing their as they pass through the rabbit's digestive tract. Seeds consumed by rabbits showed a germination proportion of $30.73 \%$ whereas control seeds showed a $29.20 \%$ of germination. Significant differences in germination rate were found in summer $(\mathrm{N}=87 ; \mathrm{Z}=-2.11 ; \mathrm{p}<0.05)$, where the ingested seeds had a higher germination rate, and in winter $(\mathrm{N}=87 ; \mathrm{Z}=-5.30$; $\mathrm{p}<0.05)$, where the control had a higher germination rate (Fig. 2).

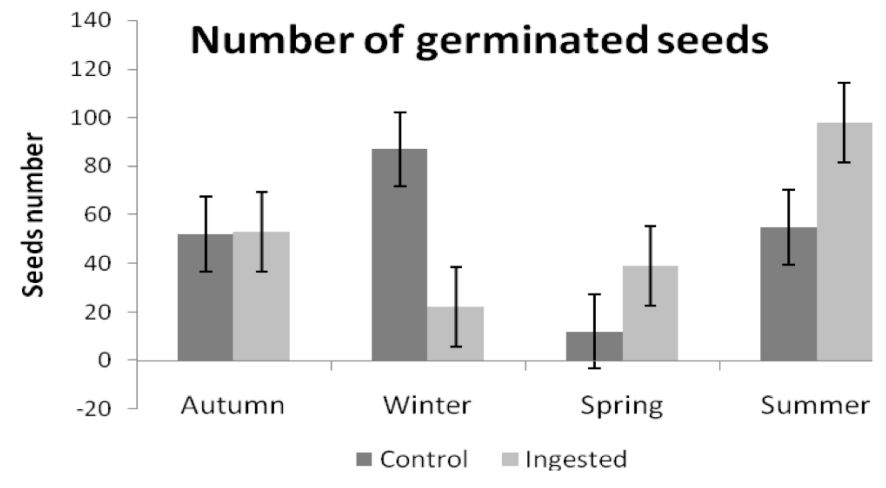

Fig. (2). Number of germinated seeds by season.

Significant differences in the number of seeds germinated by season were detected in the control $\left(\mathrm{N}=87 ; \mathrm{X}^{2}=38.47\right.$; $\mathrm{p}<0.05)$ and the ingested seeds $\left(\mathrm{N}=87 ; \mathrm{X}^{2}=15.09 ; \mathrm{p}<0.05\right)$. These results indicate that the germinating capacity varies throughout the year. The seeds taken from pods had a greater capacity of germination in autumn and winter, probably because some of them are not completely mature in the other seasons, whereas the seeds collected from rabbit pellets showed a greater germination capacity in summer and autumn.

Around $50 \%$ of the seed from pellets germinated during the first week of the experiment, whereas the seeds obtained from pods reached this percentage after 17 days of sowing. Accumulative germination curves (Fig. 3) show an earlier germination of the seeds consumed by rabbits with respect to the control seeds.

Table 1. Number of Recollected Pellets, Found and Viable Seeds, and Ingested and Control Germinated Seeds in the Different Seasons

\begin{tabular}{|l|c|c|c|c|c|}
\hline & Autumn & Winter & Spring & Summer & Total Number \\
\hline \hline Rabbit pellets & 2,004 & 1,736 & 1,577 & 1,736 & 7,080 \\
\hline A. farnesiana seeds & 216 & 173 & 165 & 238 & 792 \\
\hline Viable seeds & 177 & 147 & 165 & 203 & 592 \\
\hline Germinated control seeds & 52 & 87 & 12 & 39 & 98 \\
\hline Germinated ingested seeds & 53 & 22 & 39 & 212 \\
\hline
\end{tabular}




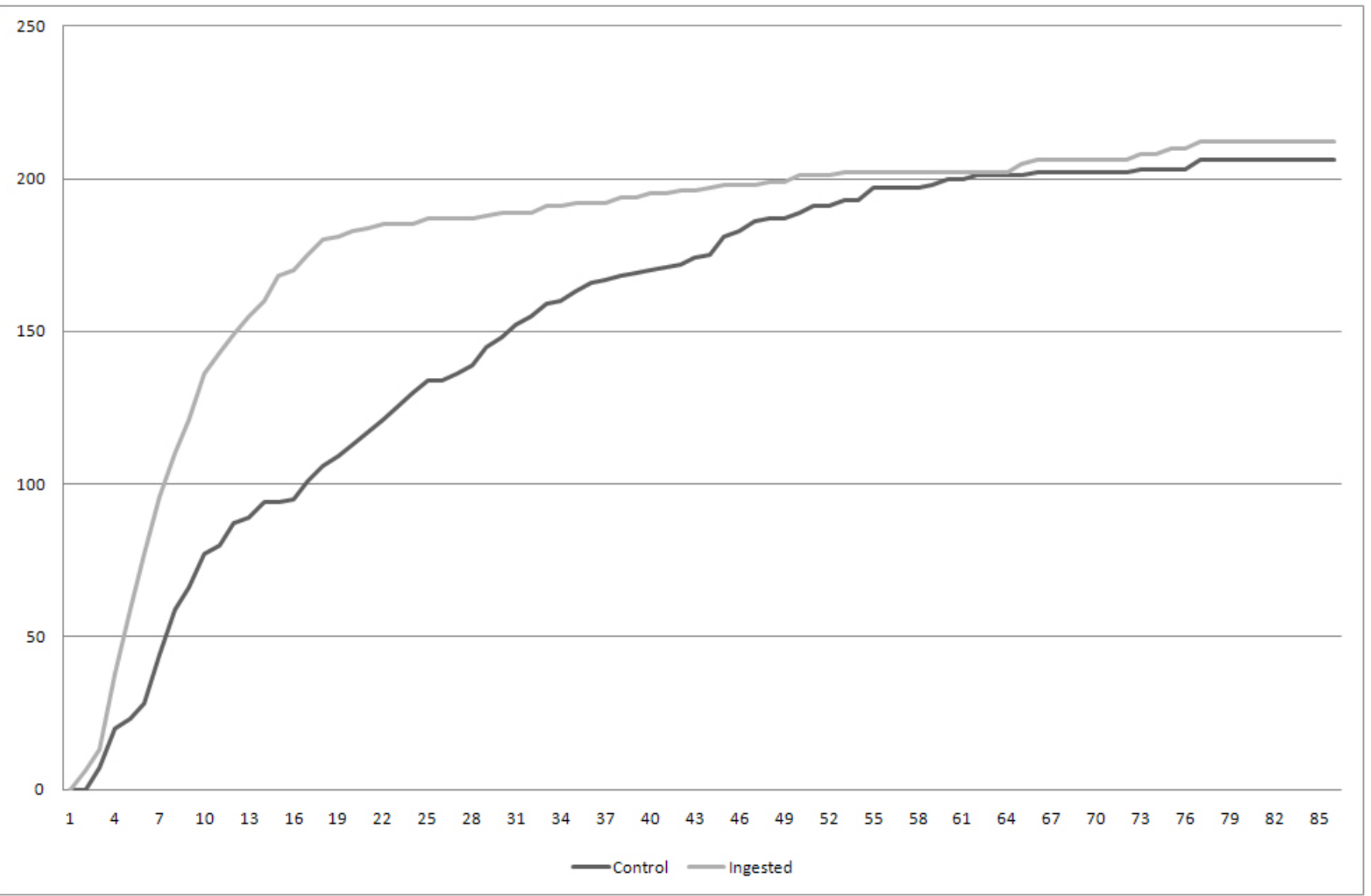

Fig. (3). Accumulative germination curves for control and ingested seeds, the speed of germination is considerably faster by the ingested seeds.

\section{DISCUSSION}

The results suggest that rabbits act as dispersing agent through endozoochory of the seeds of $A$. farnesiana. The proportion of viable seeds found in rabbit faeces, $9.77 \%$, is even higher than those observed for other Fabaceae species in rabbit's original area (3\% Retama sphaerocarpa [26]; $2.4 \%$ Retama monosperma [13]). Other research focused on the dispersal action of the rabbits on exotic plants found even higher proportions of viable seeds in the rabbit faeces [15].

The similar proportion of seeds found in the rabbit pellets between the different seasons indicates that $A$. farnesiana is a food resource that the rabbits use all year long. This continuous feeding by rabbits on $A$. farnesiana pods increases the probabilities of dispersion under favourable conditions for seedling establishment. Rabbits can contribute to the short and long-distance dispersion of the ingested seed [13], which can facilitate the expansion of the invasive $A$. farnesiana to another ravines and riverbeds, making the invading action faster and more successful.

Passage through the rabbit gut did not consistently increase the germination rate of the seeds of $A$. farnesiana. The lack of a clear action on the rate of germinated seeds, like happens with other vegetation species which share the territory naturally with rabbits $[13,26]$, indicates that rabbits are not the natural disperser of $A$. farnesiana. Although the amount of germinated seeds was similar between ingested and control seeds, clear differences existed between them in the progression of its germination. Apparently, the passage of the seeds through rabbit's digestive tract speeds up germination. The mechanical and chemical scarification of the seeds due to the ingestion by rabbits can favour the water entrance into the seed accelerating the germination progress.

Our germinated data have been collected under favourable conditions for the germination with a constant hydration of the seeds. However, the field environment in which we can found this species is very different. The territory where A. farnesiana grows around the entire world is arid or semi-arid $[14,27]$ and the seeds rarely ever have the possibility of remaining moist for a long amount of time. Because of this the territories invaded are frequently riverbeds, road side channels, in other words places with favourable water conditions [28]. The earlier germination of the seeds after passing through the rabbit gut can make possible for some seeds to grow outside of this humid atmosphere, because they need a lesser investment of water to germinate than the non-ingested seeds. This situation can allow A. farnesiana to colonise dryer territories and therefore extend the invaded area.

In conclusion, the results of this study suggest that the European rabbits are favouring the spread of the invasive scrub A. farnesiana along the Arguneguín ravine by endozoochory, making possible its establishment in areas where the water acts as the main limiting factor for the vegetation. 


\section{ACKNOWLEDGEMENTS}

This work is part of the study program of exotic species carried out by the Invasive Species: Interinsular Research Group (EIGI) of the University of La Laguna and University of Las Palmas de Gran Canaria. We thank the "Consejería de Educación, Cultura y Deportes, Gobierno de Canarias" (Regional Government Department of Education, Culture and Sports) for providing funding for this project (Code: PI042004/096). We thank the students of Geography of University of Las Palmas de Gran Canaria and the University of La Laguna for their assistance in the sampling. We are also grateful for the collaboration of the fine staff of the Cabildo de Gran Canaria (especially Mr. Carlos Velázquez) for access to the study site and collaboration with the members of this project. We appreciate the criticism and suggestions that highly improved the quality of this manuscript provided by an anonymous reviewer.

\section{REFERENCES}

[1] Olesen JM, Eskildsen LI, Venkatasamy S. Invasion of pollination networks on oceanic islands: importance of invaders complexes and endemic super generalist. Divers Distrib 2002; 8: 181-92.

[2] Simberloff D, von Holle B. Positive interactions of nonindigenous species: invasional meltdown? Biol Invasions 1999; 1: 21-32.

[3] Traveset A, Morales C, Nogales M, Padrón B, Bartomeus I. Los mutualismos facilitan las invasiones y las invasoras impactan sobre los mutualismos nativos. In: Vilá M, Valladares $\mathrm{F}$, Traveset A, Santamaría L, Castro P, Eds. Invasiones Biológicas, Madrid, CSIC, MCI, Gobierno de España 2008; pp. 77-89.

[4] Soriguer RC. The rabbit as a plant disperser. Mammal Rev 1986; 16: 197-98.

[5] Soriguer RC. Alimentación del conejo (Oryctolagus cuniculus L. 1758) en Doñana, SO, España. Doñana Acta Vertebrata 1988; 15: $141-50$.

[6] Lehrer WP, Tisdale W. Effect of sheep and rabbit digestion on the viability of some range plant seeds. J Range Manage 1956; 9: 1182 .

[7] Malo JE, Jiménez B, Suárez F. Seed bank build-up in small disturbance in a Mediterranean pasture: the contribution of endozoochorous dispersal rabbits. Ecography 1995; 18: 73-82.

[8] Pakeman RJ, Engelen J, Attwood JP. Rabbit endozoochory and seed bank build-up in an acidic grassland. Plant Ecol 1999; 145: 83-90.

[9] Malo JE, Suárez F. Herbivorous mammals as seed dispersers in a Mediterranean dehesa. Oecologia 1995; 104: 246-55.

[10] Malo JE, Jiménez B, Suárez F. Herbivore dunging and endozoochorous seed deposition in a Mediterranean dehesa. J Range Manage 2000; 53: 322-8.
[11] Stamford RJ, Cavers PB. The importance of cottontail rabbits in the dispersal of Polygonum spp. J Appl Ecol 1977; 14: 261-7.

[12] Marques C, Mathias ML. The diet of the European wild rabbit, Oryctolagus cuniculus (L.), on different coastal habitats of Central Portugal. Mammalia 2001; 65: 437-49.

[13] Dellafiore CM, Muñoz VS, Gallego FJB. Rabbits (Oryctolagus cuniculus) as dispersers of Retama monosperma seeds in a coastal dune system. Ecoscience 2006; 13: 5-10.

[14] Castro SA, Bozinovic F, Jaksic FM. Ecological efficiency and legitimacy in seed dispersal of an endemic shrub (Lithrea caustica) by the European rabbit (Oryctolagus cuniculus) in central Chile. J Arid Environ 2008; 72: 164-73.

[15] Fernández, A, Sáiz F. The european rabbit (Oryctolagus cuniculus L.) as seed disperser of the invasive opium poppy (Papaver somniferum L.) in Robinson Crusoe Island, Chile. Mastozool Neotrop 2007; 14: 19-27.

[16] Doran JC, Boland DJ, Turnbull JW, Gunn BV. Manual sobre las semillas de acacias de zonas secas. Roma: Departamento de Agricultura FAO; 1983.

[17] Oudtshorn RK, Van RMW. Dispersal Biology of Desert Plants (Adaptations of Desert Organisms). Berlin: Springer 1999.

[18] Miller MF. Dispersal of Acacia seeds by Ungulates and Ostriches in an African Savanna. J Trop Ecol 1996; 3: 345-56.

[19] Miller MF. The costs and benefits of Acacia seed consumption by ungulates. Oikos 1994; 71: 181-7.

[20] Miller MF, Coen M. Is it advantageous for Acacia seeds to be eaten by ungulates? Oikos 1993; 66: 364-8.

[21] Sanz-Elorza M, Dana ED, Sobrino E. Aproximación al listado de plantas vasculares alóctonas invasoras reales y potenciales en las islas Canarias. Lazaroa 2005; 26: 55-66.

[22] Kunkel G. Notes on the introduced elements in the Canary Island's Flora. In: Kunkel G Ed. Biogeography and ecology in the Canary Islands. Junk, La Haya 1976; pp. 249-66.

[23] Zar JH. Biostatistical analysis. $2^{\text {nd }}$ ed. Englewood Cliffs: PrenticeHall; 1984

[24] SPSS/PC+ V.6.0. Base manual. Chicago: SPSS Inc. 1986.

[25] Auld, TD. Regeneration in populations of the arid zone plants Acacia carnei and A. oswaldii. Proc Ecol Soc Aust 1990; 16: 267 72.

[26] Malo JE, Yanes M. Endozoocoria o depredación? La ingestión de legumbres de Retama sphaerocarpa por el conejo (Oryctolagus cuniculus). In: Actas de la XXXIX Reunión Científica de la Sociedad Española para el Estudio de los Pastos; 1999: pp. 93-8.

[27] Parrota JA. The role of plantations forests in rehabilitating degraded tropical ecosystems. Agric Ecosyst Environ 1992; 41: 115-33.

[28] Smith CW. Impact of Alien Plants on Hawaii's Native Biota. In: Stone CP, Scott JM, Eds. Hawaii's terrestrial ecosystems: preservation and Management. Manoa, Cooperative National Park Resources Studies Unit, University of Hawaii 1985. 